\title{
Uji Reaktor Gasifikasi Downdraft Biomassa Sampah Kota
}

\section{Putu Angga Yuda Pratama1), I Nyoman Suprapta Winaya'2), ( Gede Putu Agus Suryawan ${ }^{3)}$}

\author{
1) Program Studi Teknik Mesin, Fakultas Teknik, Universitas Udayana. \\ Kampus Bukit Jimbaran, Badung, Bali, Indonesia 80361 \\ ${ }^{2,3)}$ Jurusan Teknik Mesin, Fakultas Teknik, Universitas Udayana \\ Kampus Bukit Jimbaran, Badung, Bali, Indonesia 80361 \\ Email: anggadi30@gmail.com, nswinaya@gmail.com, suryaagus77@gmail.com
}

doi: https://doi.org/10.24843/METTEK.2019.v05.i02.p08

\begin{abstract}
Abstrak
Teknologi gasifikasi tipe downdraft adalah salah satu teknologi untuk mengkonversikan bahan bakar padat atau biomassa padat secara thermokimia dengan temperatur $600^{\circ}-700^{\circ}$ C menjadi bahan bakar gas mampu bakar dengan kebutuhan udara $20-40 \%$ Stoikiometri dimana suplai udara masuk dari atas menuju dasar reaktor dan proses gasifikasi terjadi di dasar reaktor. Sampah kota atau ( Municipal Solid Westes) adalah bahan buangan yang terdiri dari bahan organik dan anorganik yang mempunyai nilai kalor sehingga dapat digunakan sebagai bahan bakar. Penelitian ini bertujuan untuk mengetahui performansi dari gasifier tipe $d$ wondraft dengan variasi perlakuan awal bahan bakar kering, pellet, dan briket. Perbedaan perlakuan bahan bakar akan menghasilkan nilai kalor dan karakteristik bahan bakar yang berbeda sehingga nantinya akan didapatkan bahan bakar yang paling efektif. Hasil penelitian menunjukan bahwa efisiensi tertinggi didapatkan pada variasi perlakuan awal bahan bakar sampah kota yang di briketkan yaitu sebesar $61,32 \%$ dan FCR tertinggi terjadi pada bahan bakar pellet yaitu 4,61 kg/jam.
\end{abstract}

Kata Kunci : Gasifikasi Downdraft, Sampah kota kering, Pellet, Briket, Efisiensi

\begin{abstract}
Gasification type Downdraft technology is one technology to convert thermochemical solid or biomass fuels with temperatures of $600^{\circ}-700^{\circ} \mathrm{C}$ into combustible gas fuels with air requirements of 20 - 40\% Stoichiometry where the supply of air enters from above to the reactor base and gasification process occurs at the bottom of the reactor. Municipal solid waste is a waste material consisting of organic and inorganic materials that has a heating value, so that it can be used as fuel of gasification. This study aims to determine the performance of the dwondraft gasifier with variations in the pretreatment of dry $M S W$, pellets and briquettes. Differences in fuel treatment will produce different heating values and fuel characteristics so that the most effective fuel will be found later. The results showed that the highest efficiency was found in the variation of initial treatment municipal solid waste briquettes which was $61,32 \%$, and the highest FCR occurs in pellet fuel which is $4.61 \mathrm{~kg} /$ hour.
\end{abstract}

Keywords: Downdraft Gasification, Dry Municipal solid Waste, Pellet, Briquette, Efficiency 


\section{PENDAHULUAN}

Bali merupakan salah satu destinasi wisata yang terkenal di dunia dengan jumlah wisatawan yang berkunjung ke Bali terus bertambah setiap tahunnya. Seiring dengan pertumbuhan jumlah wisatawan, diikuti dengan peningkatan jumlah sampah yang semakin hari bertambah banyak. Total jumlah sampah yang dihasilkan kota Denpasar di tahun 2018 sebanyak $3.046 \mathrm{~m}^{3} /$ hari atau 914 ton/hari dan terus meningkat setiap tahunnya (DLHK Kota Denpasar). Energi biomassa adalah sumber energi alternatif yang sangat potensial di Indonesia.. Kekayaan vegetasi yang dimiliki Indonesia meliputi di bidang kehutanan, pertanian, dan perkebunan menyebabkan melimpahnya sumber energi biomassa, baik berbentuk bahan baku ataupun limbah.

Teknologi gasifikasi adalah salah satu cara yang efektif dalam mengatasi masalah sampah padat karena produk yang dihasilkan dari proses gasifikasi berupa bahan bakar gas. Menurut Rinovianto (2012) proses gasifikasi adalah proses konversi bahan bakar padat menjadi gas mampu bakar (flammable gas) melalui proses thermokimia dengan temperatur $600-700^{\circ} \mathrm{C}$ dan suplai udara terbatas (20-40\% udara stoikiometri). Proses gasifikasi terjadi di dalam reaktor gasifier dan menghasilkan gas $\mathrm{CO}, \mathrm{H}_{2}$, dan syn-gas. Bahan bakar gas yang dihasilkan adalah berupa energi kimia yang dapat dikonversikan menjadi energi panas, dan energi gerak atau energi mekanik.

Penelitian yang dilakukan oleh Feiqiang Guo et al (2014)., berbahan dasar tongkol jagung (corn stalk) kering dengan metode memvariasikan Equivalence Ratio (ER) 0,18 0,37 dan didapatkan hasil bahwa pada ER 0,25 - 0,27 dihasilkan gas dalam kondisi terbaik dengan Low Heating Value (LHV) sekitar $5400 \mathrm{~kJ} / \mathrm{m}^{3}$ dan cold gas efficiency sebesar $65 \%$.

Berdasarkan nilai kalor yang tertinggi dimiliki oleh sampah makanan yang berupa sampah organik, dan sampah plastik mempunyai nilai kalor tertinggi kedua setelah sampah makanan. Sehingga jika penelitian ini menggunakan sampah kota sebagai bahan bakar dengan penambahan sampah plastik sebanyak 5\% dari volume sampah organik, diharapkan efisiensi gasifikasi akan meningkat dan energi yang dihasilkan juga lebih besar daripada bahan bakar lainnya. Maka dari itu, penelitian yang akan dilakukan adalah tentang variasi perlakuan awal bahan bakar (kering, pellet, briket) pada proses gasifikasi biomassa sampah kota dengan sistem downdraft kontinyu. Tujuan dari penelitian ini adalah untuk mengetahui performansi terbaik dari reaktor gasifikasi downdraft dengan bahan bakar yang divariasikan yaitu dalam bentuk kering, pellet, dan briket. Parameter yang ditetapkan pada penelitian ini adalah ER dan AFR pada mode gasifikasi.

\section{TINJAUAN PUSTAKA Teknologi Gasifikasi}

Teknologi gasifikasi merupakan salah satu upaya dalam penanggulangan krisis energi fosil yang ketersediaannya mulai menipis. Teknologi gasifikasi menggunakan bahan bakar organik berupa biomassa sehingga tidak mencemari lingkungan dan sangat efektif untuk menekan jumlah sampah yang semakin hari semakin meningkat.

Gasifkasi merupakan proses konversi bahan bakar padat atau cair menjadi bahan bakar gas tanpa menghasilkan limbah atau residu karbon padat. Gasifkasi merupakan salah satu bentuk konversi yang sangat penting karena dapat secara efektif dimanfaatkan untuk desentralisasi pembangkit daya dan penerapan pemanfaatan panas. Menurut Purwantana (2007), gasifkasi juga merupakan teknologi konversi energi yang dapat digunakan untuk berbagai macam bahan bakar biomassa. Produk dari proses gasifikasi terdiri dari karbon monoksida, karbon dioksida, hidrogen, metana, dan gas-gas lain, dalam perbandingannya 
ojs.unud.ac.id/index.php/mettek

tergantung pada reaktan tertentu dan kondisi operasi (temperatur dan tekanan) yang dilakukan dalam reactor

\section{Biomassa}

Biomassa adalah bahan bakar yang dapat diperbaharui dan secara umum berasal dari makhluk hidup (non-fosil) yang di dalamnya tersimpan energi. Dalam definisi lain, biomassa merupakan keseluruhan materi yang berasal dari makhluk hidup, termasuk bahan organik yang hidup maupun yang mati, baik di atas permukaan tanah maupun yang ada di bawah permukaan tanah. Biomassa merupakan produk fotosintesa dimana energi yang diserap digunakan untuk mengkonversi karbon dioksida dengan air menjadi senyawa karbon, hidrogen, dan oksigen. Biomasa bersifat mudah didapatkan, ramah lingkungan dan terbarukan.

\section{Briket}

Suhartoyo (2017) mengatakan bahwa briket merupakan bahan bakar padat yang terbuat dari campuran biomassa, bahan bakar padat ini merupakan bahan bakar alternatif yang paling murah dan dapat dikembangkan secara massal dalam waktu yang relatif singkat mengingat teknologi dan peralatan yang relatif sederhana.

Dari penelitian yang dilakukan oleh Patabang (2012) briket arang dapat dibuat dengan dua cara, yaitu dengan membuat arang kemudian dihaluskan dan dibuat briket atau dapat juga membentuk briket dengan cara dimampatkan, kemudian diarangkan. Hasil penelitian dari Patabang (2012), didapatkan nilai kalor briket arang sekam padi sebesar $2789 \mathrm{kal} / \mathrm{g}$. Pada penelitian ini proses pembuatan

\section{Pellet}

Bahan bakar pellet merupakan salah satu bahan bakar padat yang dibentuk dengan proses pemanasan dan penekanan untuk merekatkan biomassa dengan kandungan lignin sebagai perekat. Pellet biasanya terbuat dari biomassa serbuk kayu dan biomassa lainnya yang mempunyai kandungan lignin yang tinggi. Berdasarkan hasil uji nilai kalor wood pellet dengan suhu pemanasan $60^{\circ} \mathrm{C}$ dengan bahan baku kayu kembang yang dilakukan oleh Arsada (2013) nilai kalor wood pellet yaitu 3970,98 - 4050,08 kal/g.

\section{METODE}

Penelitian ini dilakukan secara eksperimental yang meliputi preparasi reaktor gasifikasi dwondraft gasifier dan pengujian komposisi syn-gas yang dihasilkan, laju konsumsi bahan bakar, lama nyala api dan efisiensi gasifikasi yang dikontrol secara ketat dalam penelitian. Studi eksperimental bersifat sistematis dan logis sehingga hasil dari penelitian ini memiliki kemampuan pembuktian yang lebih kuat dibandingkan jenis penelitian dengan metode pendekatan yang berbeda.

Penelitian dirancang sesuai dengan tujuan pelaksanaan penelitian yang ingin mencari pengaruh ketiga variasi perlakuan biomassa sampah kota terhadap performansi reaktor gasifikasi downdraft. Dalam penelitian ini, hasil penelitian diperoleh melalui perbandingan komposisi syn-gas, laju konsumsi bahan bakar, lama nyala api dan efisiensi gasifikasi antara bahan bakar yang telah diberi perlakuan dengan yang tidak.

\section{HASIL DAN PEMBAHASAN}

\section{Karakterisasi Bahan Bakar Sampah Kota}

Pengujian atau karakterisasi bahan bakar dilakukan untuk mengetahui kandungan dan kondisi dari sampah kota yang akan kita uji. Ada 4 pengujian yang dilakukan pada bahan 
bakar yaitu analisis proximate, analisis ultimate, analisis nilai kalor, dan Thermo Gravimetric Analysis (TGA).

Tabel 1 Data Uji Proximate Bahan Bakar Sampah Kota

\begin{tabular}{ccccc}
\hline Bahan bakar & Moisture \% & $\begin{array}{c}\text { Kandungan Abu } \\
\text { \% }\end{array}$ & Fixed Carbon \% & $\begin{array}{c}\text { Volatile Metter } \\
\text { \% }\end{array}$ \\
\hline Sampah Kota & 8,65 & 8,16 & 3,38 & 79,81 \\
\hline
\end{tabular}

Tabel 2 Data Uji Ultimate Bahan Bakar Sampah Kota

\begin{tabular}{cccccc}
\hline Bahan Bakar & Sulfur \% & Nitrogen \% & Karbon \% & Oksigen \% & Hidrogen \% \\
\hline Sampah Kota & 0,05 & 0,52 & 64,46 & 18,03 & 11,50
\end{tabular}

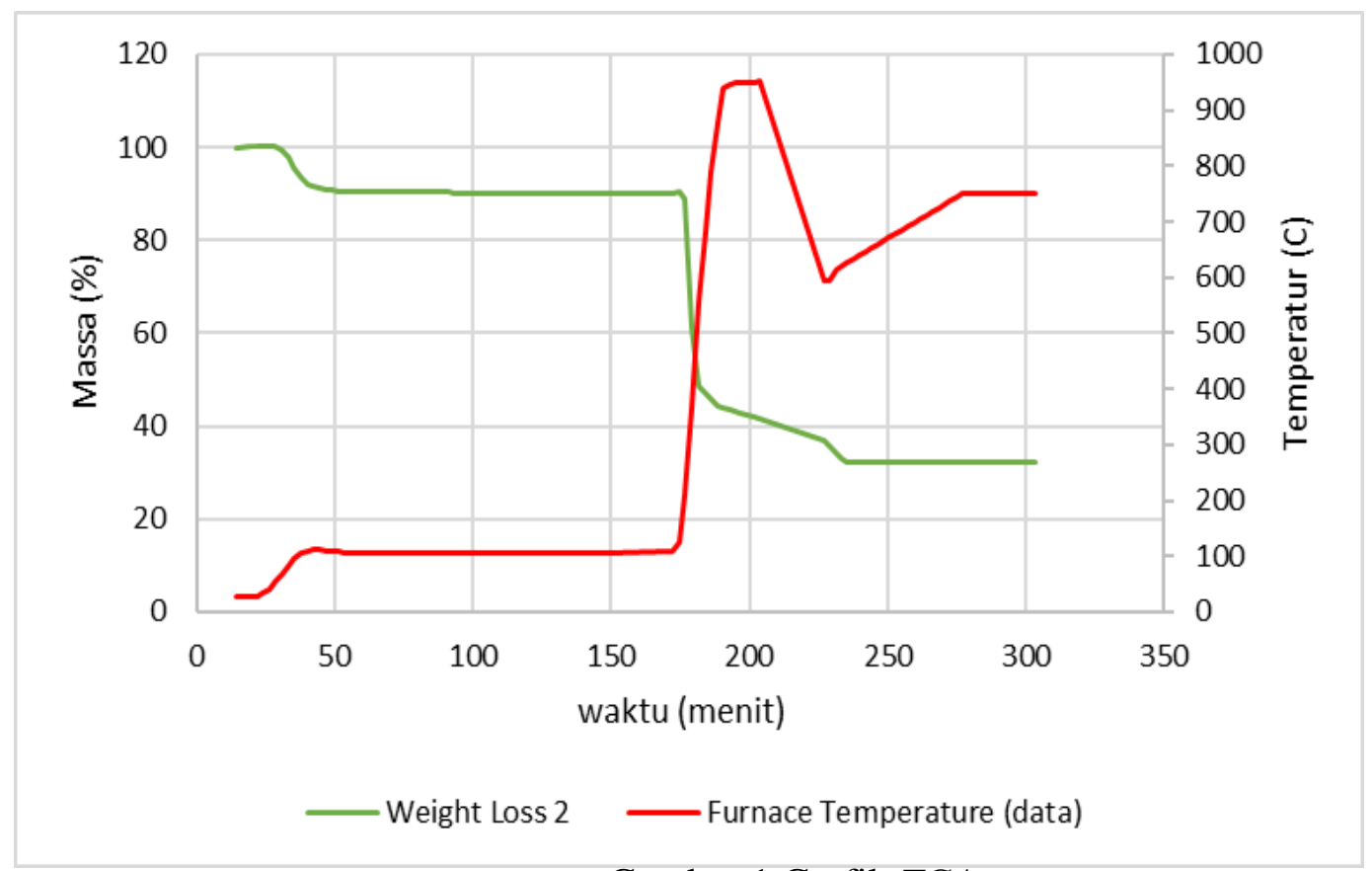

Gambar 1.Grafik TGA

\section{Data Hasil Penelitian}

Setelah melakukan penelitian dan pengamatan seperti yang telah dijelaskan pada metodologi penelitian, maka dapat diketahui data berupa waktu operasi, lama nyala api, temperature pada tiap titik yang telah ditentukan, kecepatan aliran udara, massa output dan massa input. Waktu operasi adalah durasi lama proses percobaan gasifikasi dari awal memasukkan bahan bakar, terciptanya gas mampu bakar hingga gas mampu bakar habis untuk $1 \mathrm{~kg}$ bahan bakar. Temperatur dapat diketahui dari letak Thermocouple yang sudah dipasang pada bagian tengah reaktor secara vertikal yaitu atas, bawah, dan tengah. Lama nyala api dihitung dari awal nyala syn-gas sampai habis sedangkan massa input dan output dihitung dari berat bahan bakar yang memasuki reaktor dan berat arang hasil gasifikasi. Laju aliran syngas dihitung dengan cara mengukur kecepatan output syngas menggunakan anemometer dan mengalikannya dengan luas penampang pipa output berdiameter 1 inch 
Jurnal METTEK Volume 5 No 2 (2019) pp 110 - 118

ISSN 2502-0829

ojs.unud.ac.id/index.php/mettek

Tabel 3 Data Hasil Penelitian

\begin{tabular}{|c|c|c|c|c|c|c|c|c|c|}
\hline \multirow{2}{*}{$\begin{array}{l}\text { Variasi } \\
\text { Bahan } \\
\text { Bakar }\end{array}$} & \multirow{2}{*}{$\begin{array}{l}\text { Waktu } \\
\text { Operasional } \\
\text { (menit) }\end{array}$} & \multicolumn{3}{|c|}{ Temperatur Gasifikasi } & \multirow{2}{*}{$\begin{array}{c}\text { Lama } \\
\text { Nyala } \\
\text { (menit) }\end{array}$} & \multirow{2}{*}{$\begin{array}{l}\text { Massa } \\
\text { input } \\
\text { (gram) }\end{array}$} & \multirow{2}{*}{$\begin{array}{l}\text { Massa } \\
\text { Output } \\
\text { (gram) }\end{array}$} & \multirow{2}{*}{$\begin{array}{c}\text { Kecepatan } \\
\text { output syn- } \\
\text { gas } \mathrm{m} / \mathrm{s}\end{array}$} & \multirow{2}{*}{$\begin{array}{c}\text { Laju } \\
\text { aliran } \\
\text { Syn-gas } \\
\mathbf{m}^{3} / \mathrm{s}\end{array}$} \\
\hline & & $\mathrm{T} 1\left({ }^{0} \mathrm{C}\right)$ & $\mathrm{T} 2\left({ }^{0} \mathrm{C}\right)$ & $\mathrm{T} 3\left({ }^{0} \mathrm{C}\right)$ & & & & & \\
\hline Kering & 41 & 673 & 499 & 52 & 15 & 1000 & 100 & 2,10 & 0,00102 \\
\hline Pellet & 57 & 810 & 350 & 90 & 8 & 1000 & 400 & 2,25 & 0,00110 \\
\hline Briket & 37 & 790 & 123 & 50 & 21 & 1000 & 130 & 2,19 & 0,00107 \\
\hline
\end{tabular}

Menghitung Fuel Conversion Rate (FCR)

A. Variasi I (bahan bakar sampah kota kering)

$$
F C R=\frac{\text { Berat Bahan bakar }- \text { Berat Arang }}{\text { Lama nyala }}
$$

Tabel 4 FCR dari Masing-masing Variasi Bahan Bakar

\begin{tabular}{ccccc}
\hline $\begin{array}{c}\text { Variasi } \\
\text { Perlakuan Awal } \\
\text { Bahan Bakar }\end{array}$ & $\begin{array}{c}\text { Massa Bahan } \\
\text { Bakar (kg) }\end{array}$ & $\begin{array}{c}\text { Massa Arang } \\
(\mathbf{k g})\end{array}$ & $\begin{array}{c}\text { Lama Nyala } \\
\text { (menit) }\end{array}$ & FCR (kg/jam) \\
\hline $\begin{array}{c}\text { Variasi I (bahan } \\
\text { bakar kering) }\end{array}$ & 1 & 0,1 & 15 & 3,60 \\
\hline $\begin{array}{c}\text { Variasi II (bahan } \\
\text { bakar pellet) }\end{array}$ & 1 & 0,4 & 8 & 4,61 \\
\hline $\begin{array}{c}\text { Variasi III (bahan } \\
\text { bakar briket) }\end{array}$ & 1 & 0,39 & 21 & 1,42 \\
\hline
\end{tabular}

Berdasarkan tabel diatas, FCRa (Fuel Consumtion Rate Actual) dari masing-masing variasi bahan bakar dapat digambarkan dalam bentuk grafik dibawah ini :

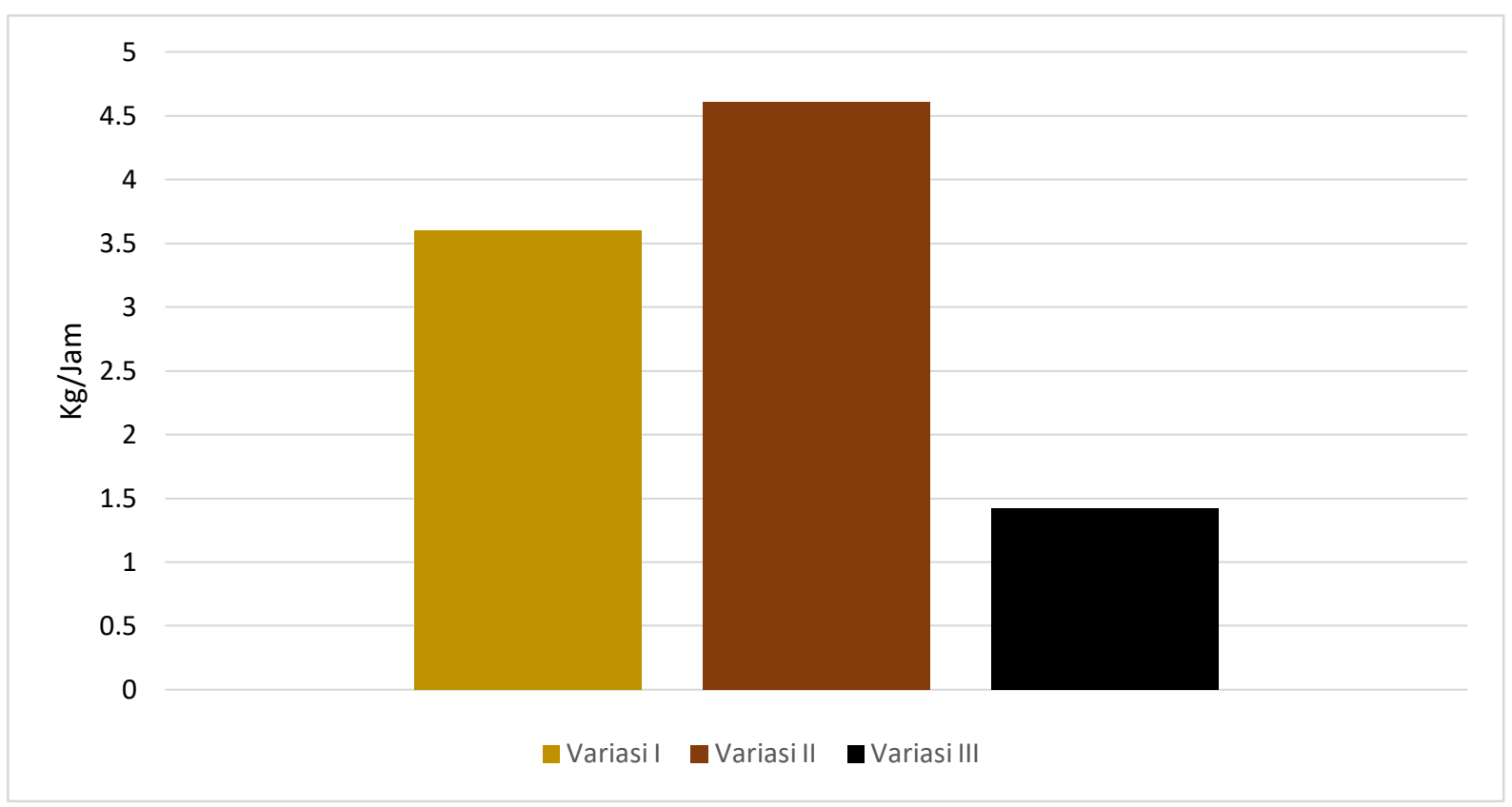

Gambar 2 Grafik FCR 


\section{Data Hasil Pengujian Syn-Gas}

Setelah dilakukan pengujian pada masing-masing variasi bahan bakar, selanjutnya gas yang dihasilkan akan di uji untuk mengetahui kandungan gas hasil gasifikasi. Pengujian dilakukan di Laboratorium Forensik Poltabes Denpasar.

A. Hasil Pengujian Variasi I (bahan bakar kering)

Tabel 5 Abudance Gas Variasi I

\begin{tabular}{|c|c|c|c|}
\hline Berat Molekul & Nama Unsur & Abudance Gas & Abudance Udara \\
\hline 14 & & 165 & \\
\hline 16 & Metana & 695 & 514 \\
\hline 17 & & 9949 & 5502 \\
\hline 18 & Air & 45544 & 23416 \\
\hline \multicolumn{4}{|l|}{20} \\
\hline \multicolumn{4}{|l|}{26} \\
\hline \multicolumn{4}{|l|}{26.90} \\
\hline \multirow{2}{*}{28} & Nitrogen Molekul & \multirow{2}{*}{7551} & \multirow{2}{*}{3772} \\
\hline & Karbon Monoksida & & \\
\hline \multicolumn{4}{|l|}{29.10} \\
\hline 32 & Oksigen Molekul & 1688 & 1143 \\
\hline \multicolumn{4}{|l|}{39.10} \\
\hline 40 & Argon & 159 & 151 \\
\hline \multicolumn{4}{|l|}{41} \\
\hline \multicolumn{4}{|l|}{42.10} \\
\hline 44 & Karbon Dioksida & 998 & 1471 \\
\hline \multicolumn{4}{|l|}{44.90} \\
\hline & & 66749 & 35969 \\
\hline
\end{tabular}

Pada uji gasifikasi downdraft, gas mampu bakar yang dicari adalah Karbon Monoksida (CO), Metana $\left(\mathrm{CH}_{4}\right)$, dan Hidrogen $\left(\mathrm{H}_{2}\right)$. Unsur Nitrogen dan Karbon Monoksida sama-sama memiliki berat molekul 28, jadi untuk mengetahui abudance $\mathrm{CO}$, harus ditentukan dulu nilai abudance dari $\mathrm{N}_{2}$ dengan persamaan sebagai berikut :

- Menentukan nilai abudance $\mathrm{N}_{2}$

Abudance $\mathrm{N}_{2}$ Gas $=\frac{\text { Nilai Abudance N2 Udara }}{\text { Nilai Abudance AR Udara }} \times$ Nilai Abudance AR Gas

- Menghitung Nilai Abudance CO

Abudance $\mathrm{CO}$ Gas $=$ Nilai abudance berat molekul $28-$ Nilai abudance $\mathrm{N}_{2}$ gas

Persentase Gas CO = $\quad=\frac{\text { Nilai Abudance Gas CO }}{\text { Nilai Abudance Gas Total }} \times 100 \%$

- Persentase $\mathrm{Gas}_{2}=100 \%-\left(\% \mathrm{CO}+\% \mathrm{CO}_{2}+\% \mathrm{CH}_{4}+\% \mathrm{H}_{2} \mathrm{O}+\% \mathrm{O}_{2}+\right.$ 
Jurnal METTEK Volume 5 No 2 (2019) pp 110 - 118

ISSN 2502-0829

ojs.unud.ac.id/index.php/mettek

$$
\begin{aligned}
& \left.\% \mathrm{~N}_{2}\right) \\
= & 100 \%-(5,36 \%+1,50 \%+1,04 \%+68,23 \%+2,53 \\
& \%+5,95 \%) \\
= & 100 \%-(84,61 \%) \\
= & 15,39 \%
\end{aligned}
$$

Hasil perhitungan jumlah kandungan gas mampu bakar pada variasi I menggunakan bahan bakar kering dapat ditampilkan pada tabel berikut :

Tabel 6 Persentase Kandungan Syn-Gas Variasi I

\begin{tabular}{ccccccc}
\hline $\mathrm{CO}$ & $\mathrm{CO}_{2}$ & $\mathrm{CH}_{4}$ & $\mathrm{H}_{2} \mathrm{O}$ & $\mathrm{O}_{2}$ & $\mathrm{~N}_{2}$ & $\mathrm{H}_{2}$ \\
\hline $5,36 \%$ & $1,50 \%$ & $1,04 \%$ & $68,23 \%$ & $2,53 \%$ & $5,95 \%$ & $15,39 \%$ \\
\hline
\end{tabular}

Pada variasi selanjutnya, pengolahan data hasil pengujian akan langsung ditampilkan dalam bentuk tabel dengan perhitungan menggunakan persamaan yang sama dengan variasi I.

B. Hasil Pengujian Variasi II (bahan bakar pellet)

Tabel 7 Persentase Kandungan Syn-Gas Variasi II

\begin{tabular}{ccccccc}
\hline $\mathrm{CO}$ & $\mathrm{CO}_{2}$ & $\mathrm{CH}_{4}$ & $\mathrm{H}_{2} \mathrm{O}$ & $\mathrm{O}_{2}$ & $\mathrm{~N}_{2}$ & $\mathrm{H}_{2}$ \\
\hline $2,75 \%$ & $2.20 \%$ & $2,54 \%$ & $66,04 \%$ & $3,17 \%$ & $7,89 \%$ & $15,41 \%$ \\
\hline
\end{tabular}

C. Hasil Pengujian Variasi III (bahan bakar briket)

Tabel 8 Persentase Kandungan Syn-Gas Variasi III

\begin{tabular}{ccccccc}
\hline $\mathrm{CO}$ & $\mathrm{CO}_{2}$ & $\mathrm{CH}_{4}$ & $\mathrm{H}_{2} \mathrm{O}$ & $\mathrm{O}_{2}$ & $\mathrm{~N}_{2}$ & $\mathrm{H}_{2}$ \\
\hline $6,38 \%$ & $12,96 \%$ & $1,31 \%$ & $52,86 \%$ & $2,70 \%$ & $8,91 \%$ & $14.88 \%$ \\
\hline
\end{tabular}

Setelah didapatkan persentase kandungan gas mampu bakar pada masing-masing variasi, maka hasil perhitungan diatas dapat disimpulkan pada tabel berikut :

Tabel 9 Kandungan Syn-gas Masing-masing Variasi

\begin{tabular}{ccccc}
\hline $\begin{array}{c}\text { Variasi Bahan } \\
\text { Bakar }\end{array}$ & $\mathrm{CO} \%$ & $\mathrm{CH}_{4} \%$ & $\mathrm{H}_{2} \%$ & Total \% \\
\hline $\begin{array}{c}\text { Bahan bakar } \\
\text { kering }\end{array}$ & 5,36 & 1,04 & 15,39 & 21,79 \\
\hline $\begin{array}{c}\text { Bahan bakar } \\
\text { pellet }\end{array}$ & 2,75 & 2,54 & 15,41 & 20,70 \\
\hline $\begin{array}{c}\text { Bahan bakar } \\
\text { briket }\end{array}$ & 6,38 & 1,31 & 14,88 & 22.57 \\
\hline
\end{tabular}

\section{Cold Gas Efficiency}

Cold gas efficiency $\left(\eta_{\mathrm{CG}}\right)$ merupakan perbandingan antara energi kimia yang dihasilkan oleh syngas (didapatkan dari perkalian antara laju alir massa dengan Nilai Kalor Bawah gas) dengan energi kimia dari biomassa (didapatkan dari perkalian antara laju alir massa biomassa dengan Nilai Kalor Bawah biomassa. Berdasarkan data hasil uji nilai kalor bahan bakar, dan pengukuran laju aliran syn-gas pada saat pengujian, maka efisiensi gasifikasi dapat diketahui dengan cara berikut :

1. Efisiensi Variasi I (bahan bakar sampah kota kering)

- Menghitung LHV bahan bakar :

$$
\begin{aligned}
\mathrm{LHV}_{\mathrm{BB}} & =\mathrm{HHV}_{\mathrm{BB}}-2400\left(\text { Moisture }+9 \mathrm{H}_{2}\right) \\
& =3843,93 \mathrm{kKal} / \mathrm{kg}-2400(0,0865+9(0,1539)) \\
& =3843,93-2679,84 \\
& =1164,1 \mathrm{kkal} / \mathrm{kg}
\end{aligned}
$$


- Menghitung LHV syn-gas :

$\mathrm{LHV}_{\text {sg }}=2762,68 \mathrm{kKal} / \mathrm{m}^{3}(\mathrm{CO})+7832,66 \mathrm{kKal} / \mathrm{m}^{3}\left(\mathrm{CH}_{4}\right)+2360,90 \mathrm{kKal} / \mathrm{m}^{3}$

$$
\begin{aligned}
& \left(\mathrm{H}_{2}\right) \\
= & 2762,68 \mathrm{kKal} / \mathrm{m}^{3}(0,0536)+7832,66 \mathrm{kKal} / \mathrm{m}^{3}(0,0104)+2360,90
\end{aligned}
$$$$
\mathrm{kKal} / \mathrm{m}^{3}(0,1539)
$$$$
=148,07+81,46+363,34
$$

$=592,87 \mathrm{kKal} / \mathrm{m}^{3}$

- Menentukan mass flowrate bahan bakar variasi I

$$
\begin{aligned}
M F_{b b} & =\frac{\text { massa bahan bakar-berat arang }}{\text { lama nyala }} \\
& =\frac{1 \mathrm{~kg}-0,1 \mathrm{~kg}}{15 \text { menit }} \\
& =0,06 \mathrm{~kg} / \mathrm{menit} \\
& =0,001 \mathrm{~kg} / \mathrm{s}
\end{aligned}
$$

- Menentukan flowrate syn-gas

Berdasarkan data di atas, laju aliran syn-gas adalah : 0,00102 $\mathrm{m}^{3} / \mathrm{s}$

- Menghitung cold gas efisiensi

$$
\begin{aligned}
\mathrm{\eta}_{\mathrm{g}} \quad & =\frac{\text { flowrate syngas } \times \text { LHV syngas }}{\text { mass flowrate } B B \times \text { LHV BB }} \times 100 \% \\
& =\frac{0,00102 \frac{\mathrm{m} 3}{\mathrm{~s}} \times 592,87 \frac{\mathrm{kKal}}{\mathrm{m} 3}}{0,001 \frac{\mathrm{kg}}{\mathrm{s}} \times 1164,1 \frac{\mathrm{kKal}}{\mathrm{kg}}} \times 100 \% \\
& =\frac{0,605 \frac{\mathrm{kKal}}{\mathrm{s}}}{1,164 \frac{\mathrm{kKal}}{\mathrm{s}}} \times 100 \% \\
& =51,89 \%
\end{aligned}
$$

Berdasarkan data hasil perhitungan diatas, dapat ditampilkan dalam bentuk tabel dan grafik dibawah ini

Tabel 10 Efisiensi Gasifikasi

\begin{tabular}{cc}
\hline Variasi Bahan bakar & Efisiensi Gasifikasi \\
\hline Variasi I (kering) & $51,89 \%$ \\
\hline Variasi II (pellet) & $48,28 \%$ \\
\hline Variasi III (briket) & $61,32 \%$ \\
\hline
\end{tabular}

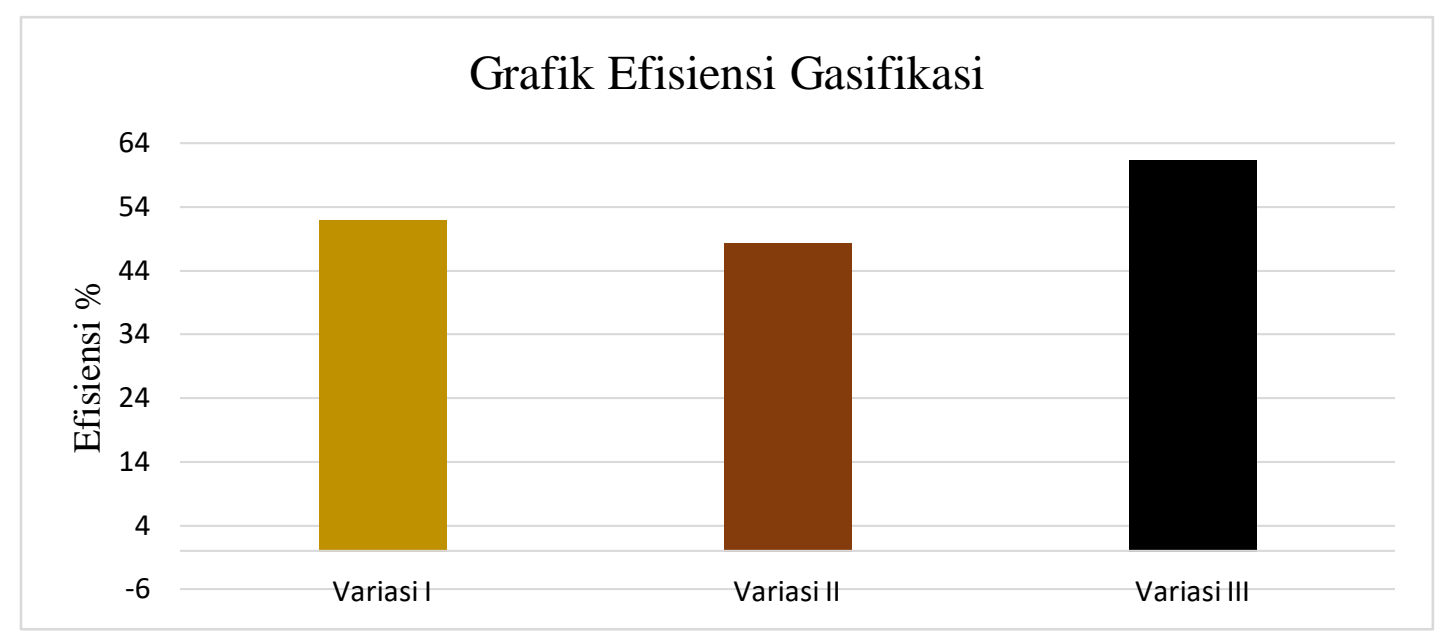

Gambar 3 Grafik Efisiensi Gasifikasi 


\section{SIMPULAN}

Setelah dilakukan penelitian dan pengujian performansi gasifikasi downdraft, didapatkan $F C R$ dari variasi I, II, dan III adalah $3,60 \mathrm{~kg} / \mathrm{jam}, 4,61 \mathrm{~kg} / \mathrm{jam}$, dan $1,42 \mathrm{~kg} / \mathrm{jam}$, serta didapatkan juga besaran AFR aktualnya yaitu, 33,56 liter/menit, 42,98 liter/menit, dan 13,24 liter/menit. Sedangkan efisiensi terbaik didapatkan dengan variasi III yaitu perlakuan awal bahan bakar yang di briketkan sebesar $61,32 \%$. Efisiensi terendah didapatkan pada variasi II yaitu bahan bakar pellet dengan efisiensi $49,78 \%$.

\section{DAFTAR PUSTAKA}

[1] Arsada, E. (2014). Sifat Fisik Dan Kimia Wood Pellet Dari Limbah Industri Perkayuan Sebagai Sumber Energi Alternatif. Jurnal Riset Industri Hasil Hutan. Vol.6. No.1. Juni 2014. Balai Riset dan Standardisasi Industri Banjarbaru.

[2] Guo, F., Dong, Y., Dong, L., Guo, C. 2014. Effect of Design and Operating Parameters on the Gasification Process of Biomass in a Downdraft Fixed Bed: An Experimental Study. Science Direct International Journal of Hydrogen Energy. Volume 39. Issue 11. Pages 5625-5633.

[3] Patabang, D. (2012). Karakteristik Termal Briket Arang Sekam Padi Dengan Variasi Bahan Perekat. Jurnal Mekanikal. Vol. 3. No. 2. Juli 2012. Jurusan Teknik Mesin, Fakultas Teknik, Universitas Tadulako.

[4] Purwantana, B. (2007). Pengembangan Gasifier Untuk Gasifikasi Limbah Padat Pati Aren (Arenga Pinnata Wurmb). Agritech. Vol. 27. No. 3. September 2007. Universitas Gadjah Mada.

[5] Rinovianto, G. (2012). Karakteristik Gasifikasi pada Updraft Double gas Outlet Gasifier Menggunakan Bahan Bakar Kayu Karet. Universitas Indonesia. Depok.

[6] Suhartoyo, S. (2017). Effektifitas Briket Biomassa. Prosiding SNATIF Ke -4 Tahun 2017. Jurusan Teknik Mesin Akademi Teknologi Warga Surakarta. 